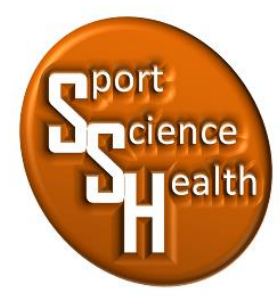

ISSN 2715-3886

\title{
Pengembangan Perangkat Pembelajaran Sepakbola Berbasis Aplikasi Articulate Storyline
}

\author{
Dimas Chandra Gunawan ${ }^{1 \star}$, Lokananta Teguh Hari Wiguno², Ari Wibowo Kurniawan³, \\ Mu'arifin ${ }^{4}$ \\ 1,2,3,4Jurusan Pendidikan Jasmani, Kesehatan dan Rekreasi, Fakultas IImu Keolahragaan, \\ Universitas Negeri Malang, Jalan Semarang No 5, Malang, Jawa Timur, 65145, Indonesia \\ *Penulis koresponden: dimaschandra733@gmail.com, 081332339399
}

Artikel diterima: 2 Maret 2021; direvisi: 16 April 2021; disetujui: 21 April 2021

\begin{abstract}
Research product development is aimed at developing a soccer learning device based on the application articulate storyline for the physical education working group elementary school in Sumbermanjing Wetan District, Malang Regency. This study uses the Research and Development method or development research. Subjects for small group trials involved 10 primary school PJOK teachers and subjects for large groups involved 41 primary school PJOKs, namely the Teacher Working Group (KKG) in Sumbermanjing Wetan District. Obtained from data analysis, namely with a percentage of $94 \%$ of learning experts, $97 \%$ of elementary game experts, $89 \%$ of physical education, sports and health experts, $99 \%$ of media experts, $95 \%$ of soccer experts, $88 \%$ the results of trial I, the percentage of $86 \%$ of the results of trial II. The conclusion in this development research is that the application development product articulate storyline is suitable to be used as a support in learning football.
\end{abstract}

Keyword: learning device; football; working group of teachers, elementary school

\begin{abstract}
Abstrak: Penelitian produk pengembangan yaitu bertujuan mengembangkan perangkat pembelajaran sepakbola berbasis aplikasi articulate storyline untuk KKG PJOK SD di Kecamatan Sumbermanjing Wetan, Kabupaten Malang. Penelitian ini menggunakan metode Research and Development atau penelitian pengembangan. Subjek untuk uji coba kelompok kecil melibatkan 10 guru PJOK SD dan subjek untuk kelompok besar melibatkan 41 PJOK SD yaitu Kelompok Kerja Guru (KKG) di Kecamatan Sumbermanjing Wetan. Didapat dari analisis data yaitu dengan persentase $94 \%$ dari ahli pembelajaran, persentase $97 \%$ ahli permainan SD, persentase $89 \%$ dari ahli pendidikan jasmani, olahraga dam kesehatan dengan, persentase $99 \%$ dari ahli media, persentase $95 \%$ dari ahli sepakbola, persentase $88 \%$ hasil uji coba I, persentase $86 \%$ hasil uji coba II. Kesimpulan dalam penelitian pengembangan ini yaitu produk pengembangan aplikasi articulate storyline ini layak dipergunakan sebagai penunjang dalam pembelajaran sepakbola.
\end{abstract}

Kata kunci: perangkat pembelajaran; sepak bola; kelompok kerja guru, sekolah dasar

\section{PENDAHULUAN}

Pendidikan jasmani adalah bentuk proses kegiatan pendidikan yang dilaksanakan dengan tujuan meningkatkan pengetahuan, keterampilan gerak dan kebugaran tubuh (Adi \& Fathoni, 2019, 2020a, 2020c). Menurut Haris (2018), dalam jurnalnya menyatakan bahwa pendidikan jasmani adalah proses pendidikan yang menggunakan aktivitas jasmani untuk mencapai tujuannya yaitu untuk perkembangan fisik, perkembangan gerak, perkembangan mental, dan perkembangan sosial. Dalam mata pelajaran pendidikan jasmani terdapat 
materi pembelajaran yang didalamnya ada materi permainan bola besar. Permainan bola besar pada umumnya yang ada di sekolah terdiri dari permainan bola voli, sepakbola, bola basket. Akan tetapi olahraga yang paling disukai dan banyak penggemarnya di seluruh dunia adalah olahraga sepakbola mulai dari kalangan anak-anak sampai lansia menyukai olahraga ini. Oleh karena itu, dalam pembelajaran sepakbola peserta didik tidak hanya dituntut untuk hanya dapat mengetahui permainan sepakbola. Akan tetapi, peserta didik harus dapat memahami dan mempraktikkan variasi dan kombinasi geraknya. Sebab itu materi pembelajaran sepakbola terkandung dalam kompetensi inti dan kompetensi dasar kelas VI yang dijelaskan dalam Permendikbud tahun 2018 sebagai berikut:

Tabel 1. Kompetensi Inti dan Kompetensi Dasar Pendidikan, Jasmani, Olahraga dan Kesehatan Kelas VI Sekolah Dasar (Permendikbud, 2018)

\begin{tabular}{|c|c|}
\hline Kompetensi Inti Pengetahuan Kelas VI & Kompetensi Inti Keterampilan Kelas VI \\
\hline $\begin{array}{l}\text { 3. Memahami pengetahuan faktual dan } \\
\text { konseptual dengan cara mengamati, } \\
\text { menanya dan mencoba berdasarkan rasa } \\
\text { ingin tahu tentang dirinya, makhluk ciptaan } \\
\text { Tuhan dan kegiatannya, dan benda-benda } \\
\text { yang dijumpainya di rumah, di sekolah dan di } \\
\text { tempat bermain. }\end{array}$ & $\begin{array}{l}\text { 4. Menyajikan pengetahuan faktual dan } \\
\text { konseptual dalam bahasa yang jelas, } \\
\text { sistematis, logis dan kritis, dalam karya yang } \\
\text { estetis, dalam gerakan yang mencerminkan } \\
\text { anak sehat, dan dalam tindakan yang } \\
\text { mencerminkan perilaku anak beriman dan } \\
\text { berakhlak mulia. }\end{array}$ \\
\hline Kompetensi Dasar Pengetahuan Kelas VI & Kompetensi Dasar Keterampilan Kelas VI \\
\hline $\begin{array}{l}\text { 3.1 Memahami variasi dan kombinasi gerak } \\
\text { dasar lokomotor, nonlokomotor, dan } \\
\text { manipulatif dengan kontrol yang baik dalam } \\
\text { permainan bola besar sederhana dan atau } \\
\text { tradisional }\end{array}$ & $\begin{array}{l}\text { 4.1 Mempraktikkan variasi dan kombinasi gerak } \\
\text { dasar lokomotor, non-lokomotor, dan } \\
\text { manipulatif dengan kontrol yang baik dalam } \\
\text { permainan bola besar sederhana dan atau } \\
\text { tradisional }\end{array}$ \\
\hline
\end{tabular}

Oleh sebab itu, guru dapat mempertimbangan dalam mengembangkan perangkat pembelajaran yang lebih efektif dan modern (Kristiono, Dwiyogo, \& Hariadi, 2019; Masgumelar, Dwiyogo, \& Nurrochmah, 2019; Pambudi, Winarno, \& Dwiyogo, 2019; Rodriquez, Dwiyogo, \& Supriyadi, 2020). Karena guru membutuhkan situasi pembelajaran yang kondusif dan menyenangkan sebagai wahana pembelajaran professional (Christianto \& Dwiyogo, 2020; Dwiyogo \& Radjah, 2020; Kurniawan, Winarno, \& Dwiyogo, 2018; Manalu, Dwiyogo, \& Heynoek, 2020). Penelitian sebelumnya menurut Munawar \& Hendrawan (2019), menyatakan bahwa hasil dari penelitian menunjukkan bahwa media pembelajaran interaktif berbasis multimedia pada mata kuliah pembelajaran sepakbola layak digunakan serta dapat digunakan media pembelajaran dengan pengembangan produk tersebut memudahkan mahasiswa dalam mengakses materi perkulihan pembelajaran sepakbola melalui aplikasi tersebut. Penelitian sebelumnya menurut Murtiyono (2016), menyatakan bahwa hasil penelitian menunjukkan bahwa produk pengembangan buku saku permainan sepakbola dapat digunakan siswa SD secara masal. siswa bependapat bahwa banyak kelebihan dari produk ini yaitu sangat baik dan tampilannya menarik, buku saku bisa dibawa kemana-mana, materi mudah dipahami, karena diperjelas dengan gambar, dengan adanya buku ini siswa dapat belajar dengan mudah untuk membantu pembelajaran sehingga dapat menigkatkan motivasi dan minat siswa-siswi untuk belajar permainan bola besar khususnya sepakbola. Penelitian sebelumnya menurut Siregar, Simatupang, \& Valianto, (2020), dalam jurnalnya menyatakan bahwa sepak bola adalah permainan sederhana sepak bola adalah olahraga tim yang dimainkan oleh masing-masing tim dari sebelas orang dengan tujuan mencetak gol ke gawang lawan. Sedanglan menurut, Maka dari itu dengan pembelajaran sepakbola peserta didik harus dapat mempraktikkan variasi gerak dasar dengan dikombinasikan dalam permainan sepakbola.

Menurut Rachmadtullah, Ms, \& Sumantri (2018), menyatakan bahwa media pembelajaran dengan berbasis komputer dapat membantu mempresentasikan materi sebagai sumber informasi tambahan yang tentunya akan memudahkan penerima atau peserta didik. Sebab itu dengan semakin berkembangnya teknologi akan memaksa guru untuk memanfaatkan teknologi sebagai penunjang dalam pembelajaran terutama untuk perangkat pembelajaran sepakbola aplikasi articulate storyline.

Perkembangan teknologi yang begitu pesat dengan mudah dapat dimanfaatkan untuk pendidikan menjadikan pengembangan perangkat sepakbola dapat diterapkan oleh guru sehingga dapat menciptakan pembelajaran yang inspiratif, menyenangkan, efektif, serta peserta didik dapat termotivasi untuk aktif,dan juga dapat 
memberikan cukup ruang, tempat menyalurkan kreativitas, memilih bakat, minat yang sesuai serta pertumbuhan fisik dan psikologis siswa (Adi \& Fathoni, 2020b; Fathoni, 2018). Beberapa cara salah satunya dengan adanya pengembangan perangkat pembelajaran sepakbola berbasis aplikasi articulate storyline. Penelitian sebelumnya menurut Pratama (2018), dalam jurnalnya menyatakan bahwa aplikasi articulate storyline merupakan alat yang digunakan untuk mempresentasikan informasi dengan tujuan tertentu. Dibutuhkan kemampuan seni dan kemampuan teknis yang dikolaborasikan agar menghasilkan karya presentasi yang menarik peserta. Penelitian sebelumnya menurut Yasin (2017), dalam jurnalnya menyatakan bahwa aplikasi Articulate Storyline menawarkan beberapa template yang cukup menarik sehingga dapat dipersingkat waktu pembuatan terutama untuk membuat soal latihan maupun soal tes. Tampilan yang sederhana akan mempermudah guru dalam mengoprerasikannya. Penelitian sebelumnya menurut Darnawati, dkk (2019), dalam jurnalnya menyatakan bahwa aplikasi articulate storyline merupakan perangkat lunak yang diciptakan tahun 2014, aplikasi ini memiliki kemampuan untuk dapat menggabungkan slide, flash (swf), video dan karakter animasi menjadi satu.

Sumbermanjing Wetan adalah satu dari beberapa kecamatan yang berada di Kabupaten Malang. Kecamatan Sumbermanjing Wetan terdapat 51 sekolah dasar (SD) dengan 51 Sekolah Dasar menurut data dari Dinas Pendidikan Koordinator Wilayah Kecamatan Sumbermanjing Wetan. Sebagian besar sekolah dasar (SD) di Kecamatan Sumbermanjing Wetan Kabupaten Malang memiliki fasilitas pendukung seperti komputer, laptop dan di setiap sekolah mayoritas memiliki proyektor (LCD) yaitu alat yang berguna sebagai sarana penunjang kegiatan pembelajaran. Guru PJOK SD di Sumbermanjing Wetan seluruhnya memiliki smartphone. Akan tetapi, alat penunjang tersebut masih belum dimanfaatkan secara maksimal untuk pembelajaran sepakbola di dalam kelas.

Berdasarkan dari observasi yang dilakukan oleh peneliti di Kecamatan Sumbermanjing Wetan Kabupaten Malang berupa analisis kebutuhan untuk KKG PJOK SD yang dilakukan oleh peneliti melalui wawancara langsung dengan ketua Kelompok Kerja Guru (KKG) PJOK SD di Kecamatan Sumbermanjing Wetan dan menyebar angket melalui google form terhadap KKG PJOK SD didapat hasil bahwa $96 \%$ guru pernah mengikuti pelatihan guru PJOK, 68\% guru menyelenggarakan materi pembelajaran sepakbola pada siswa di dalam kelas, $100 \%$ guru menggunakan perangkat pembelajaran secara manual atau print out, $100 \%$ guru belum pernah melakukan pengembangan terkait media pembelajaran sepakbola berbasis aplikasi articulate storyline, $80 \%$ guru belum pernah memanfaatkan teknologi sebagai media pembelajaran berbasis aplikasi maupun dengan media power point, video pembelajaran,dan Media lain berbasis teknologi, $84 \%$ guru masih menggunakan media pembelajaran berupa LKS dan buku ajar, 100\% sekolah guru mengajar memiliki LCD, terdapat $100 \%$ sekolah atau guru memiliki smartphone, komputer/laptop, dan terdapat $100 \%$ guru mampu mengoperasikan komputer. Sehingga peneliti menyimpulkan bahwa guru dalam pembelajaran membutuhkan perangkat pembelajaran berbasis aplikasi articulate storyline dengan materi pembelajaran sepakbola.

Berdasarkan permasalahan yang ada, maka perlu dikembangkan perangkat pembelajaran sepakbola berbasis aplikasi. Oleh sebab itu, maka peneliti mengembangkan perangkat pembelajaran sepakbola berbasis aplikasi articulate storyline untuk Kelompok Kerja Guru (KKG) PJOK Sekolah Dasar di Kecamatan Sumbermanjing Wetan sehingga dengan adanya pengembangan ini diharapkan dapat menarik minat peserta didik dalam proses pembelajaran sepakbola khususnya kelas VI.

\section{METODE}

Model penelitian pengembagan perangkat pembelajaran bola basket berbasis aplikasi articulate storyline berpedoman pada alur pengembangan Lee and Owens yang dikombinasikan dengan alur pengembangan oleh Borg \& Gall yang menggunakan pendekatan Research and Development (R\&D) dengan menyesuaikan kebutuhan penelitian dengan menggunakan tahap-tahap pengembangan sebagai berikut: 1) melaksanakan needs assessment atau analisis kebutuhan, (2) melaksanakan rancangan produk, (3) mengembangkan produk, (4) mengimplementasikan di lapangan, (5) mengevaluasi produk. Berdasarkan langkah-langkah tersebut merupakan suatu langkah-langkah dalam memecahkan permasalahan dalam penelitian dan nantinya dapat menghasilkan suatu produk. Peneliti dalam rancangan uji coba akan melaksanakan kajian berdasarkan catatan dan masukan dari lima ahli yang terdiri dari ahli pembelajaran, ahli permainan SD, ahli PJOK, ahli sepakbola, ahli media dan Kelompok Kerja Guru (KKG) PJOK Sekolah Dasar yang tergabung uji coba dalam kelompok kecil yang berjumlah 10 orang sedangkan dalam kelompok besar dengan jumlah 41 orang. Nantinya 
catatan dan saran dari para ahli dapat dijadikan pedoman dalam merevisi produk awal dalam produk peneliti. Data yang diperoleh berdasarkan tinjauan para ahli dan pelaksanaan uji coba produk yang berbentuk data kuantitatif dan kualitatif. Data kualitatif didapatkan melalui catatan dan masukan beberapa ahli. Pada dasarnya data kuantitatif didapatkan ketika uji coba kelompok kecil dan besar berupa hasil dari pengumpulan kuisioner yang berbentuk angka.

Dalam tahapan teknik menganalisis data selama melakukan penelitian yaitu menggunakan statistik deskriptif. Pengumpulan data dilakukan dengan teknik pengukuran memakai skala likert, yang dipakai dalam melihat sikap, gagasan dan persepsi individu atau suatu komunitas tertentu tentang fenomena sosial (Sugiyono, 2017: 134). Pada instrumen di skala likert memiliki kategori respon yang mencakup sangat setuju hingga tidak setuju. Dalam kebutuhan menganalisis data kuantitatif respon dapat dibubuhkan skor yang sudah dipatenkan antara lain (1), (2), (3) dan (4).

Tabel 2. Skala Evaluasi Pernyataan

\begin{tabular}{clcc}
\hline No & Kategori & Pilihan & Skor \\
\hline 1. & Sangat Setuju & A & 4 \\
2. & Setuju & B & 3 \\
3. & Ragu-ragu & C & 2 \\
4. & Tidak Setuju & D & 1 \\
\hline
\end{tabular}

Rumus dalam mendapatkan data berbentuk deskriptif kuantitatif dengan persentase yang dikatakan Akbar \& Sriwiyana, di bawah ini:

$$
\mathrm{V}=\frac{\mathrm{TSEV}}{\mathrm{S}-\max } \times 100 \%
$$

Keterangan:

V : Validitas

TSEV : Total skor empirik validator

S-max : Skor maksimal yang diharapkan

$100 \%$ : Bilangan konstanta

Kemudian sebagai memudahkan pada bagian ketepatan data hasil menganalisis persentase dapat dikaitkan pada persentase yang telah didapatkan. Penggolongan kategorisasi persentase yaitu:

Tabel 3. Parameter Status Produk (Irawan \& Japarianto, 2013)

\begin{tabular}{lll}
\hline persentase & Kategori & Arti \\
\hline $75,01 \%-100,00 \%$ & Sangat Valid & Dapat dipakai tanpa revisi \\
$50,01 \%-75,00 \%$ & Cukup Valid & Dapat dipakai dengan revisi \\
$25,01 \%-50,00 \%$ & Tidak Valid & Tidak dapat dipakai \\
$00,00 \%-25,00 \%$ & Sangat Tidak Valid & Terlarang dipakai \\
\hline
\end{tabular}

\section{HASIL}

Tujuan analisis data adalah agar dapat mengetahui kelayakan produk pengembangan perangkat pembelajaran sepakbola berbasis aplikasi articulate storyline untuk Kelompok Kerja Guru (KKG) di Kecamatan sumbermanjing Wetan, kabupaten Malang. Analisis data akan diuraikan pada bagian ini yang meliputi ahli pembelajaran, ahli permainan SD, ahli PJOK, ahli media, ahli sepakbola dan data dari hasil uji coba kecil dan besar.

\section{Ahli Pembelajaran}

Analisis data didapat dari ahli pembelajaran dengan berdasarkan 3 aspek dijabarkan pada tabel berikut ini: 
Tabel 4. Analisis Data dari Ahli Pembelajaran

\begin{tabular}{clcl}
\hline No & \multicolumn{1}{c}{ Aspek yang Dinilai } & persentase & Arti \\
\hline 1 & kejelasan & 89 & sangat valid \\
2 & ketepatan & 92 & sangat valid \\
3 & kemudahan & 100 & sangat valid \\
\hline \multicolumn{2}{r}{ Rata-Rata } & 94 & sangat valid
\end{tabular}

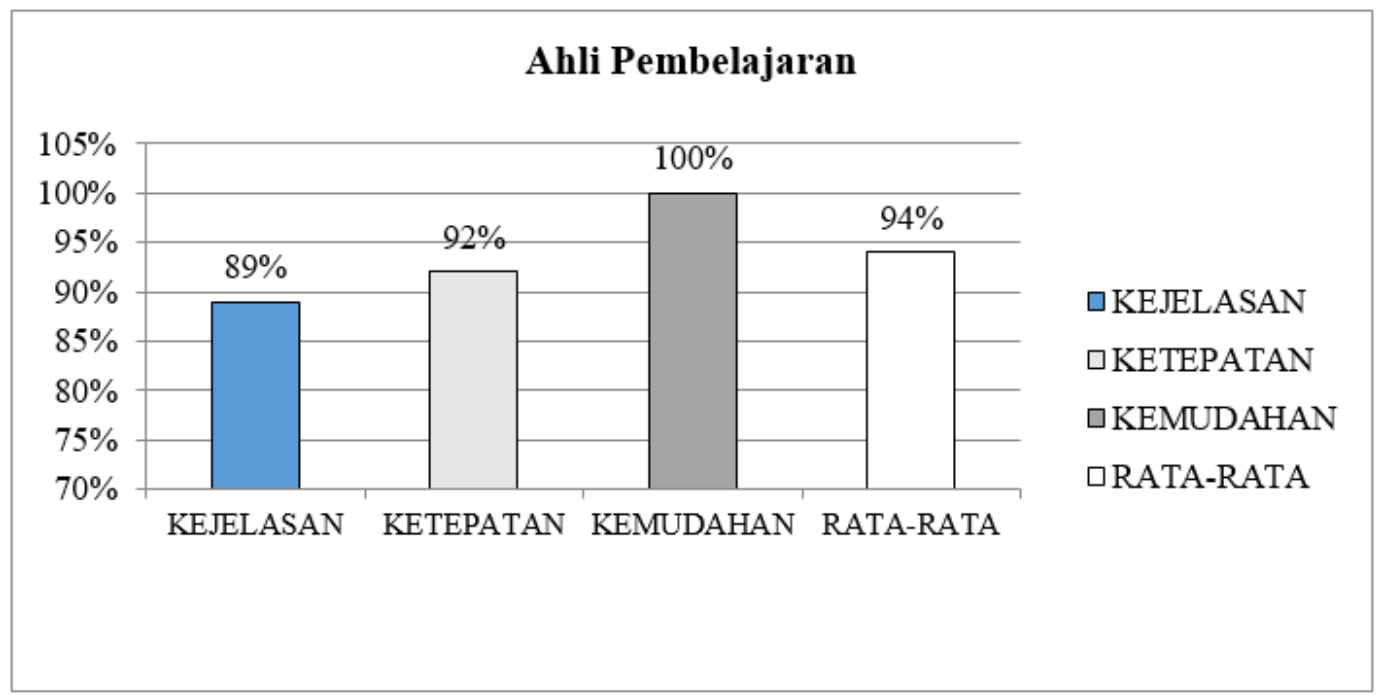

Gambar 1. Diagram Penilaian Ahli Pembelajaran

Dari hasil analisis data memperlihatkan produk pengembangan perangkat pembelajaran sepakbola berbasis aplikasi articulate storyline sudah menunjukkan klasifikasi sangat valid dengan persentase $94 \%$ berdasarkan aspek-aspek yang dinilai serta layak digunakan yang didapat dari penilaian ahli pembelajaran.

\section{Ahli Permainan SD}

Analisis data didapat dari ahli permainan SD dengan berdasarkan 5 aspek dijabarkan pada Tabel berikut ini:

Tabel 5. Analisis Data dari Ahli Permainan SD

\begin{tabular}{clcl}
\hline No & \multicolumn{1}{c}{ Aspek yang Dinilai } & persentase & Arti \\
\hline 1 & kejelasan & 94 & sangat valid \\
2 & kemudahan & 100 & sangat valid \\
3 & kemenarikan & 100 & sangat valid \\
4 & kesesuaian & 100 & sangat valid \\
5 & ketepatan & 93 & sangat valid \\
\hline \multicolumn{2}{r}{ Rata-Rata } & 97 & Sangat Valid \\
\hline
\end{tabular}




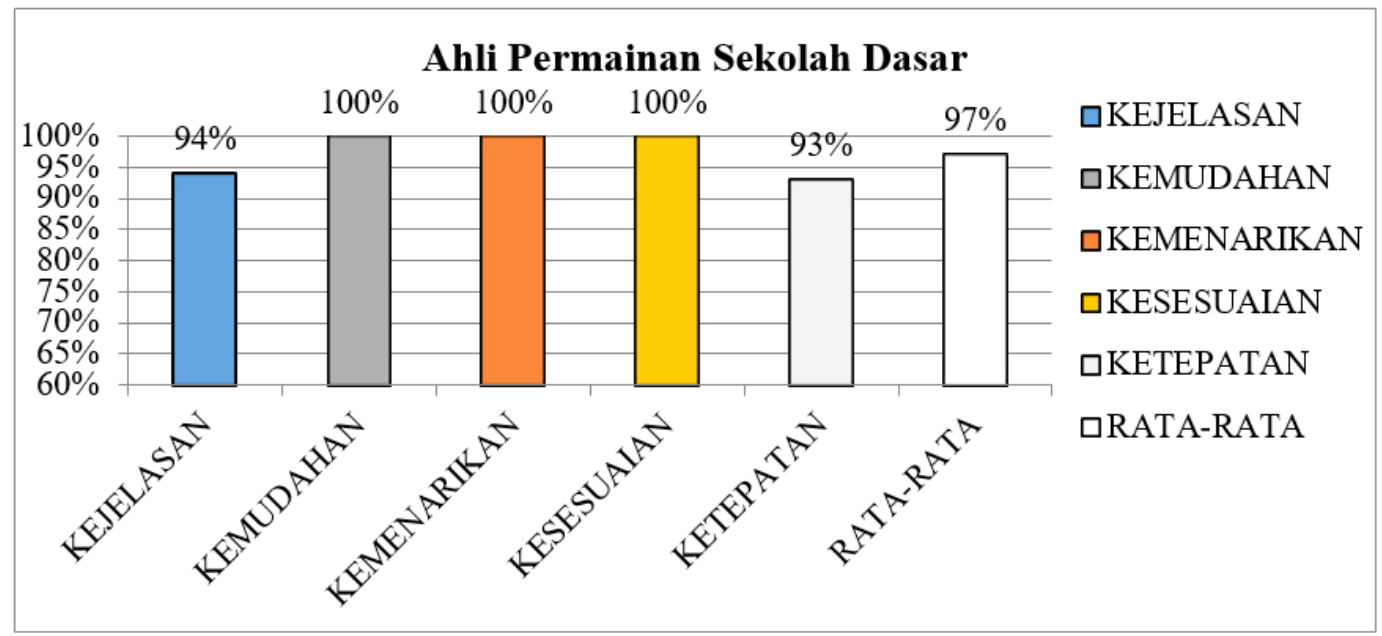

Gambar 2. Diagram Penilaian Ahli Permainan Sekolah Dasar

Dari hasil analisis data memperlihatkan produk pengembangan perangkat pembelajaran sepakbola berbasis aplikasi articulate storyline sudah menunjukkan klasifikasi sangat valid dengan persentase $97 \%$ berdasarkan aspek-aspek yang dinilai serta layak digunakan yang didapat dari penilaian ahli Permainan SD.

\section{Ahli Pendidikan Jasmani, Olahraga dan Kesehatan}

Analisis data didapat dari ahli PJOK dengan berdasarkan 5 aspek dijabarkan pada Tabel berikut ini:

Tabel 6. Analisis Data dari Ahli PJOK

\begin{tabular}{clcl}
\hline No & \multicolumn{1}{c}{ Aspek yang Dinilai } & persentase & Arti \\
\hline 1 & kejelasan & 84 & sangat valid \\
2 & kemudahan & 75 & cukup valid \\
3 & kemenarikan & 100 & sangat valid \\
4 & kesesuaian & 100 & sangat valid \\
5 & ketepatan & 86 & sangat valid \\
\hline \multicolumn{2}{r}{ Rata-Rata } & 89 & sangat valid \\
\hline
\end{tabular}

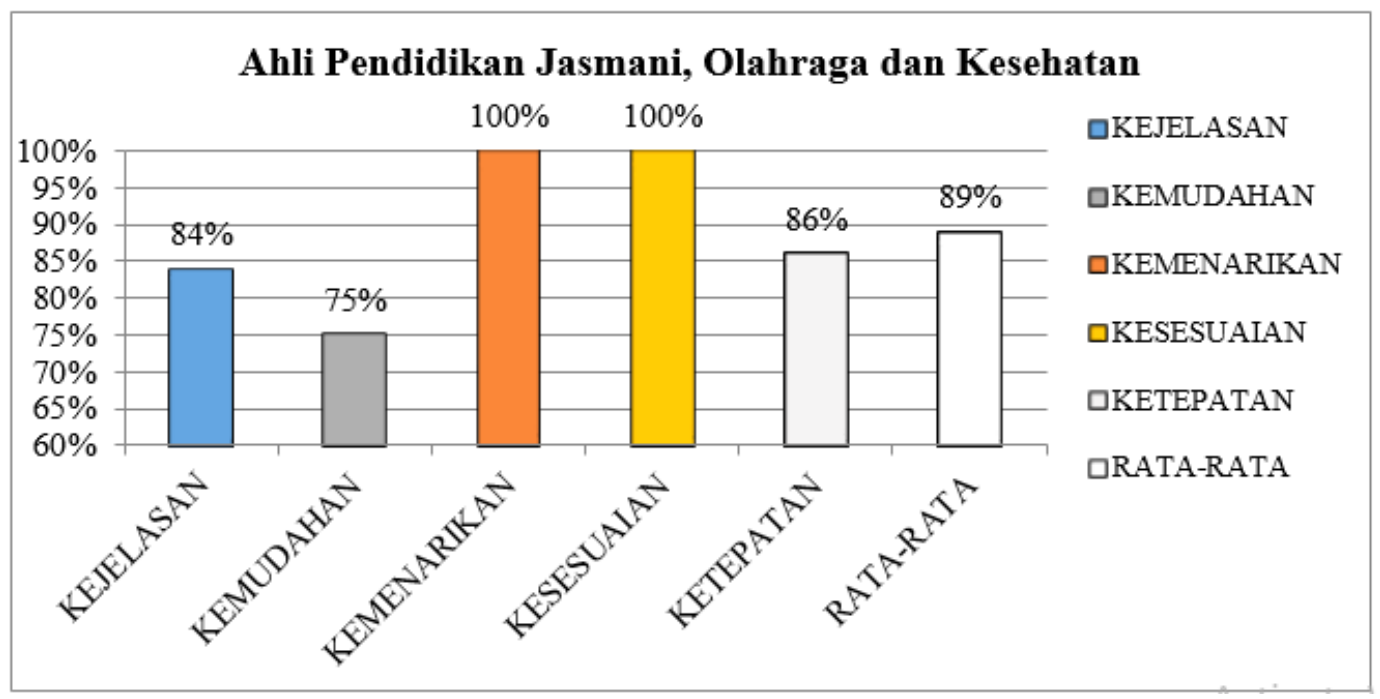

Gambar 3. Diagram Penilaian ahli PJOK

Dari hasil analisis data memperlihatkan produk pengembangan perangkat pembelajaran sepakbola berbasis aplikasi articulate storyline sudah menunjukkan klasifikasi sangat valid dengan persentase $89 \%$ berdasarkan aspek-aspek yang dinilai serta layak digunakan yang didapat dari penilaian ahli PJOK. 


\section{Ahli Media}

nalisis data didapat dari ahli media dengan berdasarkan 6 aspek pada produk pengembangan perangkat pembelajaran sepakbola berbasis aplikasi articulate storyline dijabarkan pada Tabel 7 berikut ini:

Tabel 7. Analisis Data Dari Ahli Media

\begin{tabular}{clcl}
\hline No & \multicolumn{1}{c}{ Aspek yang Dinilai } & persentase & Arti \\
\hline 1 & ketepatan & 100 & sangat valid \\
2 & kelengkapan & 100 & sangat valid \\
3 & kemudahan & 100 & sangat valid \\
4 & kemenarikan & 100 & sangat valid \\
5 & kesesuaian & 98 & sangat valid \\
6 & kejelasan & 95 & sangat valid \\
\hline & Rata-Rata & 99 & Sangat Valid
\end{tabular}

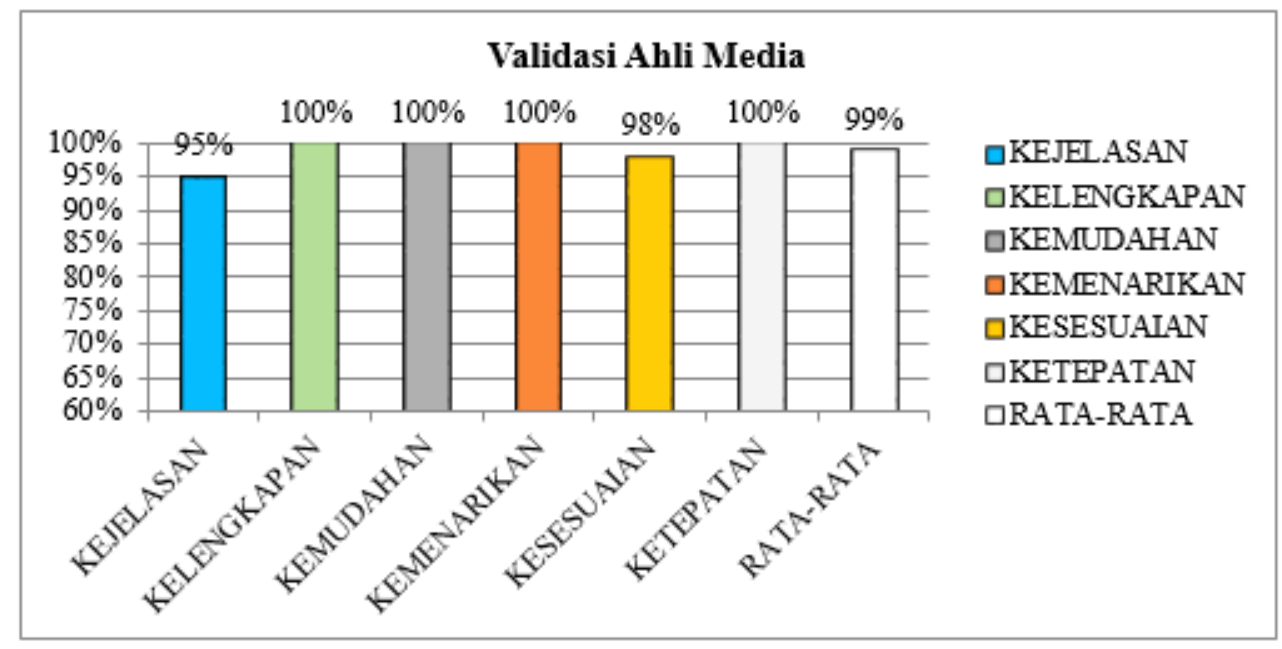

Gambar 4. Diagram Penilaian Ahli Media

Dari hasil analisis data memperlihatkan produk pengembangan perangkat pembelajaran sepakbola berbasis aplikasi articulate storyline sudah menunjukkan klasifikasi sangat valid dengan persentase $99 \%$ berdasarkan aspek-aspek yang dinilai serta layak digunakan yang didapat dari penilaian ahli media.

\section{Ahli Sepakbola}

Analisis data didapat dari ahli sepakbola dengan berdasarkan 5 aspek dijabarkan pada Tabel berikut ini:

Tabel 8. Analisis Data Dari Ahli Sepakbola

\begin{tabular}{clcl}
\hline No & \multicolumn{1}{c}{ Aspek yang Dinilai } & persentase & Arti \\
\hline 1 & kejelasan & 89 & sangat valid \\
2 & kemudahan & 100 & cukup valid \\
3 & kemenarikan & 100 & sangat valid \\
4 & kesesuaian & 88 & sangat valid \\
5 & ketepatan & 100 & sangat valid \\
\hline \multicolumn{2}{r}{ Rata-Rata } & 95 & sangat valid \\
\hline
\end{tabular}




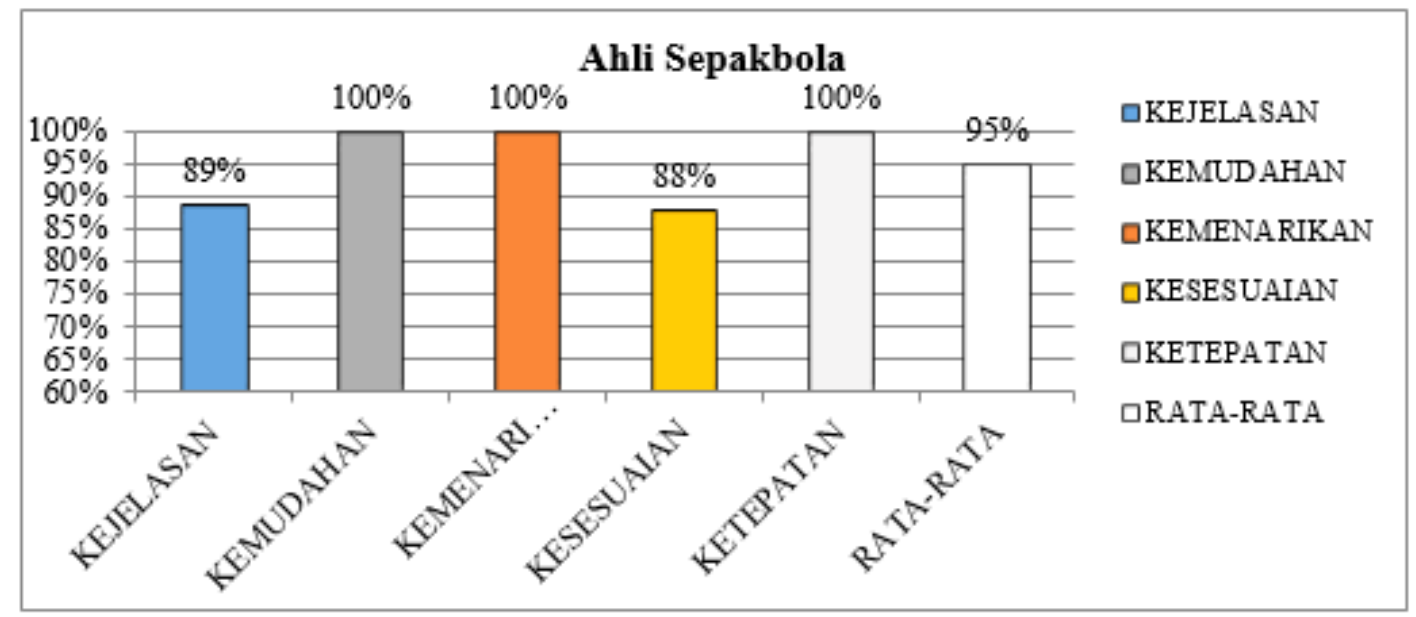

Gambar 5. Diagram Penilaian Ahli Sepakbola

Dari hasil analisis data memperlihatkan produk pengembangan perangkat pembelajaran sepakbola berbasis aplikasi articulate storyline sudah menunjukkan klasifikasi sangat valid dengan persentase $95 \%$ berdasarkan aspek-aspek yang dinilai serta layak digunakan yang didapat dari penilaian ahli sepakbola.

\section{Uji Coba Kelompok Kecil}

Analisis data didapat dari uji coba kelompok kecil dengan berdasarkan 5 aspek dijabarkan pada Tabel berikut ini:

Tabel 9. Analisis Data dari Uji Coba Kelompok Kecil Kelompok Kerja Guru (KKG) PJOK SD

\begin{tabular}{clcl}
\hline No & \multicolumn{1}{c}{ Aspek yang Dinilai } & persentase & Arti \\
\hline 1 & kejelasan & 84 & Sangat Valid \\
2 & kemudahan & 85 & Sangat Valid \\
3 & kemenarikan & 84 & Sangat Valid \\
4 & kesesuaian & 99 & Sangat Valid \\
5 & kegunaan & 89 & Sangat Valid \\
\hline \multicolumn{2}{r}{ Rata-Rata } & 88 & Sangat Valid \\
\hline
\end{tabular}

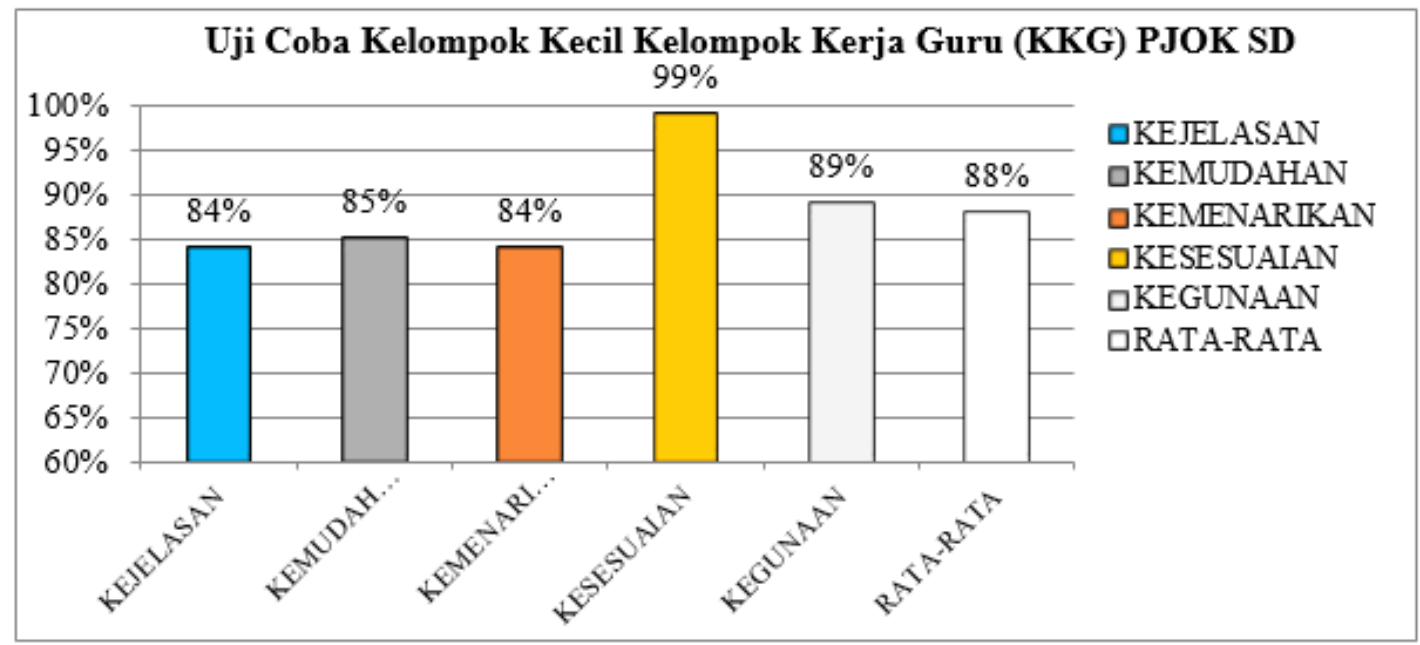

Gambar 6. Diagram penilaian Hasil Analisis Data Uji Coba Kelompok Kecil KKG PJOK SD

Dari hasil analisis data memperlihatkan produk pengembangan perangkat pembelajaran sepakbola berbasis aplikasi articulate storyline sudah menunjukkan klasifikasi sangat valid dengan persentase $88 \%$ berdasarkan aspek-aspek yang dinilai serta layak digunakan yang didapat dari hasil penilaian uji coba kelompok kecil.

\section{Uji Coba Kelompok Besar}


Analisis data didapat dari ahli uji coba kelompok besar dengan berdasarkan 5 aspek dijabarkan pada Tabel berikut ini:

Tabel 10. Analisis Data dari Uji Coba Kelompok Besar Kelompok Kerja Guru (KKG) PJOK SD

\begin{tabular}{clcl}
\hline No & \multicolumn{1}{c}{ Aspek yang Dinilai } & persentase & Arti \\
\hline 1 & kejelasan & 85 & sangat valid \\
2 & kemudahan & 86 & sangat valid \\
3 & kemenarikan & 86 & sangat valid \\
4 & kesesuaian & 86 & sangat valid \\
5 & kegunaan & 89 & sangat valid \\
\multicolumn{2}{r}{ Rata-Rata } & $\mathbf{8 6}$ & sangat valid \\
\hline
\end{tabular}

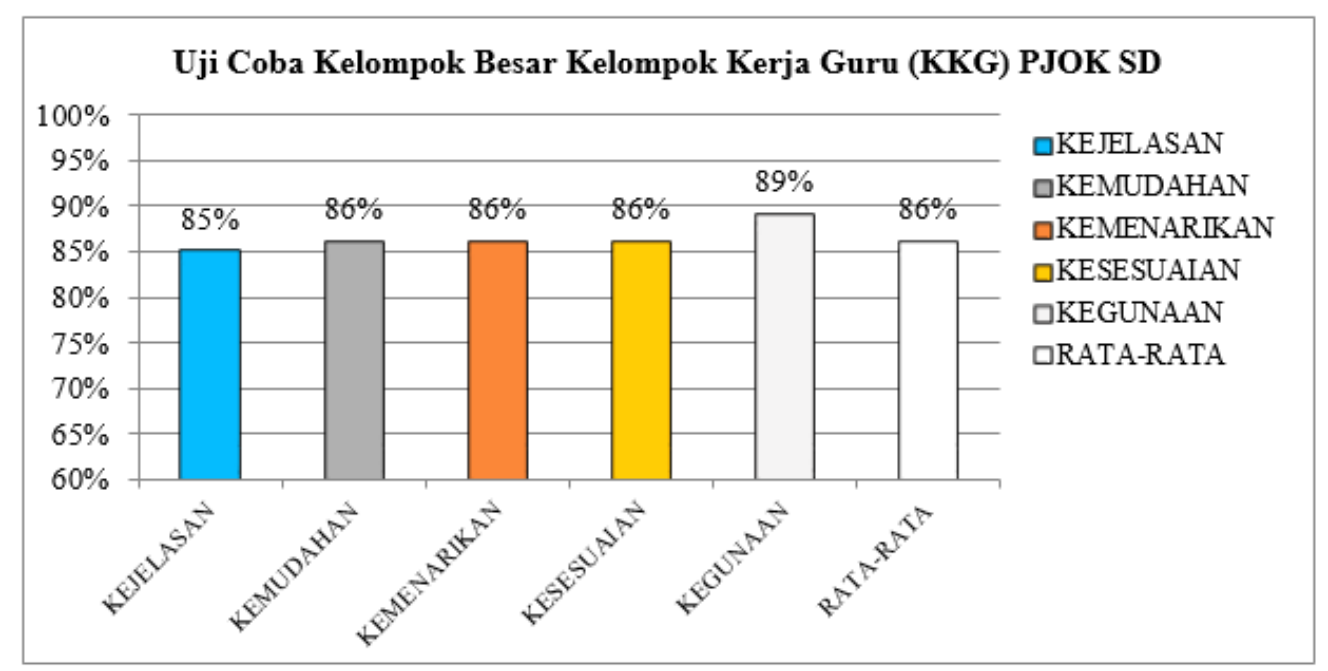

Gambar 7. Diagram Penilaian Hasil Uji Coba Kelompok Besar KKG PJOK SD

Dari hasil analisis data memperlihatkan produk pengembangan perangkat pembelajaran sepakbola berbasis aplikasi articulate storyline sudah menunjukkan klasifikasi sangat valid dengan persentase $86 \%$ berdasarkan aspek-aspek yang dinilai serta layak digunakan yang didapat dari hasil penilaian uji coba kelompok kecil.

\section{Perbaikan Produk}

Diperoleh data penilaian dari ahli yaitu melibatkan ahli pembelajaran, ahli permainan sekolah dasar, ahli pendidikan jasmani, olahraga dan kesehatan, ahli media, ahli sepakbola dan hasil uji coba I dan hasil uji coba II, yang berguna untuk dapat menyempurnakan produk pengembangan perangkat pembelajaran sepakbola berbasis aplikasi articulate storyline untuk Kelompok Kerja Guru (KKG) di Kecamatan Sumbermanjing Wetan, Kabupaten Malang, terdapat beberapa revisi yang diperoleh dari hasil saran dan masukan dijabarkan pada Tabel 11 berikut: 
Tabel 11. Data Saran dan Masukan Produk pengembangan perangkat pembelajaran sepakbola berbasis aplikasi articulate storyline untuk Kelompok Kerja Guru (KKG)

\begin{tabular}{|c|c|c|}
\hline No & Penilaian & Keterangan \\
\hline \multirow[t]{3}{*}{1.} & Ahli Pembelajaran & \\
\hline & 1. Materi sesuaikan dengan karakteristik siswa. & Telah direvisi \\
\hline & 2. Gunakan bahasa yang mudah dipahami & \\
\hline \multirow[t]{4}{*}{2.} & Ahli Permainan Sekolah Dasar & \\
\hline & 1. Gunakan gambar pada aplikasi format PNG & \\
\hline & 2. Perbanyak gerak sesuai dengan kompetensi dasar & Telah direvisi \\
\hline & 3. Petakan lagi macam-macam gerak dasar dalam sepakbola & \\
\hline \multirow[t]{3}{*}{3.} & Ahli Pendidikan Jasmani, Olahraga dan Kesehatan & \\
\hline & $\begin{array}{l}\text { 1. Tambahkan ilustrasi pada materi agar peserta didik dapat melihat } \\
\text { contoh langsung }\end{array}$ & Telah direvisi \\
\hline & 2. Pada teknik dasar lebih baik membuat ilustrasi sendiri & \\
\hline \multirow[t]{4}{*}{4.} & Ahli Media & \\
\hline & 1. Pada pilihan tombol tambahkan gambar yang menarik & \\
\hline & 2. Halaman menu ganti background yang lebih terang & Telah direvisi \\
\hline & 3. Tambah daftar pustaka jika mengutip dari sumber lain & \\
\hline \multirow[t]{5}{*}{5.} & Ahli Sepakbola & \\
\hline & 1. Teknik dasar kontrol perlu ditambah & \\
\hline & 2. Gerakan menyundul perlu direvisi & Telah direvisi \\
\hline & 3. Sarana dan prasarana diperjelas ditambah dengan contoh & \\
\hline & 4. Ditambah dengan pemanasan dinamis & \\
\hline \multirow[t]{3}{*}{6.} & Uji Coba Kelompok & \\
\hline & 1. Musik lebih baik musik nusantara atau daerah & Telah direvisi \\
\hline & 2. Halaman evaluasi harus lebih menarik & \\
\hline
\end{tabular}

\section{PEMBAHASAN}

Produk penelitian dan pengembangan ini adalah produk pengembangan perangkat pembelajaran sepakbola berbasis aplikasi articulate storyline yang menyatukan gambar, tulisan, video, dan suara yang dikemas menjadi aplikasi. Seperti halnya menurut pendapat Setyaningsih, Rusijono, \& Wahyudi (2020), menyatakan bahwa hasil belajar kelas yang menggunakan media pembelajaran articulate storyline mata pelajaran IPS meningkat $70 \%$ dari pada kelas yang belum memakai media pendukung. Penggunaan media sebagai sarana pembelajaran di sekolah bertujuan untuk siswa lebih mudah dalam memahami materi. Sehingga nantinya tujuan dalam kompetensi pembelajaran dapat dicapai, hal tersebut selaras dengan Larsson \& Karlefors, (2015), dalam jurnalnya yang mengemukakan bahwa guru bukan satu-satunya sumber belajar, sebab menjadi seorang guru harus memiliki strategi pembelajaran yang akan membantu siswa untuk memahami kegiatan pendidikan salah satunya mengembangkan media pembelajaran. Penelitian sebelumnya menurut Leow \& Neo (2014), dalam jurnalnya yang menyatakan bahwa pembelajaran yang kreatif salah satunya dengan memanfaatkan konten media yang melibatkan siswa, tanpa disadari akan meningkatkan motivasi siswa dalam proses pembelajaran yang tentunya akan berpengaruh pada hasil belajar siswa. Selaras dengan pendapat tersebut penelitian sebelumnya menurut Rahman, Kurniawan, \& Heynoek, (2020), menyatakan bahwa hasil penelitian menunjukkan bahwa produk pembelajaran kebugaran jasmani unsur kecepatan di SMA Negeri 1 Turen Layak digunakan dalam pembelajaran dan sebagai referensi sember belajar terutama mata pelajaran pendidikan jasmani kesehatan dan olahraga kelas X dan XI. Siswa lebih aktif dan sangat antusias dalam mengikuti pelajaran dalam materi kebugaran jasmani unsur kecepatan dengan menggunakan multimedia interaktif. Selaras menurut Pamungkas, I. A. \& Dwiyogo, W. D (2020), menyatakan bahwa penelitian menghasilkan produk pengembangan media pembelajaran berbasis mobile learning untuk aktifitas kesegaran jasmani siswa SMKN 1 Batu. Adapun hasil dari penelitian menunjukan nilai yang maksimal atau indeks Amat Baik, sehingga dapat disimpulkan pengembangan media pembelajaran Kebugaran jasmani sangat valid untuk digunakan untuk guru kelas, siswa, pelatih dan khalayak luas yang ingin mempelajari kebugaran jasmani. Sehingga aplikasi articulate storyline ini tergolong dalam perangkat pembelajaran yang efisien dimana produk ini berupa aplikasi android yang dapat diakses dengan mudah serta dapat digunakan sebelum pembelajaran di lapangan. Kemudian pada aplikasi articulate storyline ini berisi rencana pelaksanaan pembelajaran 
sepakbola kelas VI, materi pembelajaran kelas VI meliputi: pengertian sepakbola, sarana dan prasarana sepakbola, teknik dasar sepakbola, gerak dasar sepakbola, peraturan sepakbola, serta video pembelajaran materi kelas $\mathrm{VI}$, terdapat evaluasi penilaian untuk kelas $\mathrm{VI}$, dan biodata penulis.

Aplikasi articulate storyline juga lebih dioptimalkan pada materi pembelajaran sepakbola kelas VI yang dikemas dalam video materi pembelajaran. Terdapat 6 video materi inti pembelajaran didalam produk pengembangan pembelajaran sepakbola berbasis aplikasi articulate storyline ini. Dalam video materi yang digunakan dalam pembelajaran sepakbola berbasis aplikasi articulate storyline ini mempermudah guru dalam memberikan contoh cara meningkatkan keterampilan terutama dalam materi sepakbola disebabkan materi yang termuat dalam aplikasi articulate storyline ini mengandung materi penunjang untuk meningkatkan keterampilan teknik dasar dalam sepakbola. Hal tersebut selaras dengan Amiq, Hariadi, \& Yudasmara (2019), menyatakan bahwa sepakbola adalah cara agar melindungi bola dari lawan dan merebut bola jika bola dilindungi lawan. Sepakbola dimainkan oleh 11 orang setiap tim. Dalam sepakbola terdapat teknik dasar yang perlu dikuasai yaitu ball feeling, passing, controlling, heading, shooting, throw in, dan menangkap bola untuk penjaga gawang.

Diharapkan setelah dikembangkanya produk ini pembelajaran sepakbola akan lebih beragam dan lebih modern yang nantinya guru dapat memotivasi minat siswa, selain itu dapat menambah pengetahuan guru di bidang teknologi yang bermanfaat untuk guru dalam proses pembelajaran terutama pembelajaran sepakbola kelas VI.

\section{KESIMPULAN}

Dapat disimpulkan dari hasil penelitian dan pengembangan ini adalah produk pengembangan perangkat pembelajaran sepakbola berbasis aplikasi articulate storyline ini, produk pengembangan sepakbola berbasis aplikasi articulate storyline layak dipergunakan dalam pembelajaran sepakbola kelas 6 dan dapat dijadikan sebagai penunjang pembelajaran pada kelas VI terutama pada materi pembelajaran sepakbola.

\section{DAFTAR PUSTAKA}

Adi, S., \& Fathoni, A. F. (2019). Development of Learning Model Based on Blended Learning in Sports School. https://doi.org/10.2991/acpes-19.2019.2

Adi, S., \& Fathoni, A. F. (2020a). Blended Learning Analysis for Sports Schools in Indonesia. International Journal of Interactive Mobile Technologies (iJIM), 14(12), 149-164. Retrieved from https://www.onlinejournals.org/index.php/i-jim/index

Adi, S., \& Fathoni, A. F. (2020b). Mobile Learning sebagai Fasilitas Belajar Mandiri Pembelajaran Senam Lantai pada Mahasiswa Jurusan IImu Keolahragaan. Jurnal Pendidikan: Teori, Penelitian, Dan Pengembangan, 5(8), 1158-1166. Retrieved from http://journal.um.ac.id/index.php/jptpp/article/view/13946/6206

Adi, S., \& Fathoni, A. F. (2020c). The effectiveness and efficiency of blended learning at sport schools in Indonesia. International Journal of Innovation, Creativity and Change.

Amiq, F., Hariadi, I., \& Yudasmara, D. S. (2019). Pembentukan diklat (pendidikan dan latihan) sepakbola universitas negeri malang. Jurnal Karinov, 2(2), 93-96.

Christianto, J., \& Dwiyogo, W. D. (2020). Pengembangan Media Pembelajaran Cricket Berbasis Mobile Learning Pada Tim Olahraga Cricket Universitas Negeri Malang. Gelanggang Pendidikan Jasmani Indonesia, 3(2), 168. https://doi.org/10.17977/um040v3i2p168-174

Darnawati, Batia, L., Irawaty, \& Salim. (2019). Pemberdayaan Guru Melalui Pengembangan Multimedia Pembelajaran Interaktif Dengan Aplikasi Articulate Storyline. Jurnal Pengabdian Kepada Masyarakat, $1(1), 8-16$.

Dwiyogo, W. D., \& Radjah, C. L. (2020). Effectiveness, efficiency and instruction appeal of blended learning model. International Journal of Online and Biomedical Engineering, 16(4), 91-108. https://doi.org/10.3991/ijoe.v16i04.13389 
Fathoni, A. F. (2018). The Role of Blended Learning on Cognitive Step in Education of Sport Teaching by Adjusting the Learning Style of the Students. https://doi.org/10.2991/isphe-18.2018.49

Haris, I. N. (2018). Model Pembelajaran Peer Teaching Dalam Pembelajaran Pendidikan Jasmani. Jurnal IImiah FKIP Universitas Subang, 4(1), 2461-3961.

Irawan, D., \& Japarianto, E. (2013). Analisa Pengaruh Kualitas Produk Terhadap Loyalitas Melalui Kepuasan Sebagai Variabel Intervening Pada Pelanggan Restoran Por Kee Surabaya. Jurnal Manajemen Pemasaran.

Kristiono, I. D., Dwiyogo, W. D., \& Hariadi, I. (2019). Pembelajaran IImu Gizi Olahraga Berbasis Blended Learning pada Mahasiswa Pendidikan Jasmani, Kesehatan, dan Rekreasi. Jurnal Pendidikan: Teori, Penelitian, Dan Pengembangan, 4(2), 235-241. Retrieved from http://journal.um.ac.id/index.php/jptpp/article/view/12004

Kurniawan, R., Winarno, M. E., \& Dwiyogo, W. D. (2018). Evaluasi Pembelajaran Pendidikan Jasmani, Olahraga, dan Kesehatan pada Siswa SMA Menggunakan Model Countenance. Jurnal Pendidikan: Teori, Penelitian, Dan Pengembangan, 3(10), 1-12. Retrieved from http://journal.um.ac.id/index.php/jptpp/article/view/11599

Larsson, H., \& Karlefors, I. (2015). Physical education cultures in Sweden: fitness , sports , dancing ... learning? Physical education cultures in Sweden: fitness, sports, dancing ... learning? Sport, Education and Society, 20(5), 573-587. https://doi.org/10.1080/13573322.2014.979143

Leow, F.-T., \& Neo, M. (2014). Interactive Multimedia Learning: Innovating Classroom Education In A Malaysian University. The Turkish Online Journal of Educational Technology, 13(2), 99-110.

Manalu, D. L., Dwiyogo, W. D., \& Heynoek, F. P. (2020). Pengembangan Multimedia Interaktif Latihan Kekuatan Pada Matakuliah Spesialisasi Kondisi Fisik Dasar Untuk Mahasiswa Pendidikan Kepelatihan Olahraga Fakultas IImu Keolahragaan. Sport Science and Health, 2(1), 49-57. Retrieved from http://journal2.um.ac.id/index.php/jfik/article/view/11158

Masgumelar, N. K., Dwiyogo, W. D., \& Nurrochmah, S. (2019). Modifikasi Permainan menggunakan Blended Learning Mata Pelajaran Pendidikan Jasmani, Olahraga, dan Kesehatan. Jurnal Pendidikan: Teori, Penelitian, Dan Pengembagan, 4(7), 979-986. Retrieved from http://journal.um.ac.id/index.php/jptpp/article/view/12645

Munawar, A. Al, \& Hendrawan, D. (2019). Pengembangan Media Pembelajaran Interaktif Berbasis Multimedia Pada Mata Kuliah Pembelajaran Sepak Bola. Jurnal IImiah STOK Bina Guna Medan, 7(2), 62-69.

Murtiyono, A. T. (2016). Pengembangan Buku Saku Permainan Sepakbola Pada Siswa Di Sd Negeri li Temanggung I Kabupaten Temanggung Jawatengah. Jurnal Pengembangan Buku Saku Tahun 2016, $3(1), 1-8$.

Pambudi, M. I., Winarno, M., \& Dwiyogo, W. D. (2019). Perencanaan dan Pelaksanaan Pembelajaran Pendidikan Jasmani Olahraga Kesehatan. Jurnal Pendidikan Olahraga, Universitas Negeri Malang, 4(1), 110-116. Retrieved from http://journal.um.ac.id/index.php/jptpp/

Pamungkas, I. A., \& Dwiyogo, W. D. (2020). Pengembangan Media Pembelajaran Berbasis Mobile Learning Untuk Aktifitas Kesegaran Jasmani Siswa kelas X Sekolah Menengah Kejuruhan. Sport Science and Health, 2(5), 272-278.

Permendikbud. (2018). Peraturan Menteri Pendidikan Dan Kebudayaan Republik Indonesia Nomor 37 Tahun 2018... Tentang Perubahan Atas Peraturan Menteri Pendidikan Dan Kebudayaan Nomor 24 Tahun 2016 Tentang Kompetensi Inti Dan Kompetensi Dasar Pelajaran Pada Kurikulum 2013 Pada Pe.

Pratama, R. A. (2018). Media Pembelajaran Berbasis Articulate Storyline 2 Pada Materi Menggambar Grafik Fungsi Di Smp Patra Dharma 2 Balikpapan Learning Media Based On Articulate Storyline 2 On Drawing Function Graphs Lesson In Smp Patra Dharma 2 Balikpapan. Jurnal Dimensi, 7(1), 19-35.

Rachmadtullah, R., Ms, Z., \& Sumantri, M. S. (2018). Development of computer - based interactive multimedia : study on learning in elementary education. International Journal of Engineering \& Technology, 7(4), 2051-2054. https://doi.org/10.14419/ijet.v7i4.16384 
Rahman, Z., Kurniawan, A. W., \& Heynoek, F. P. (2020). Pengembangan Pembelajaran Kebugaran Jasmani Unsur Kecepatan Berbasis Multimedia Interaktif. Sport Science and Health, 2(1), 78-92. Retrieved from http://journal2.um.ac.id/index.php/jfik/article/view/11692/5123

Rodriquez, E. I. S., Dwiyogo, W. D., \& Supriyadi. (2020). Blended Learning Matakuliah Sepakbola untuk Mahasiswa Pendidikan Jasmani Kesehatan dan Rekreasi. Jurnal Pendidikan: Teori, Penelitian, Dan Pengembagan, 5(2), 206-213.

Setyaningsih, S., Rusijono, \& Wahyudi, A. (2020). Pengaruh Penggunaan Media Pembelajaran Interaktif Berbasis Articulate Storyline Terhadap Motivasi Belajar Dan Hasil Belajar Siswa Pada Materi Kerajaan Hindu. Jurnal Pendidikan Dan IImu Pengetahuan, 20(2), 144-156.

Siregar, F. R., Simatupang, N., \& Valianto, B. (2020). The Effect of Small Side Games Training Toward Improvement of Basic Soccer Techniques at Perfect Unimed School Students. Advances in Health Sciences Research, 23(1), 213-215. https://doi.org/10.2991/isphe

Sugiyono. (2015). Metode Penelitian Pendidikan. Bandung: Alfabeta.

Yasin, A. N. (2017). Kelayakan Teoritis Multimedia Interaktif Berbasis Articulate Storyline Materi Sistem Reproduksi Manusia Kelas XI SMA. Berkala IImiah Pendidikan Biologi, 6(2), 169-174. 